\title{
e-Spor, Spor ve Fiziksel Aktivite
}

\author{
Rüstem MUSTAFAOĞLU*1 \\ ${ }^{1}$ Ístanbul Üniversitesi-Cerrahpaşa, Sağglı Bilimleri Fakültesi, Fizyoterapi ve Rehabilitasyon Bölümü, \\ https://orcid.org/0000-0001-7030-0787
}

$\ddot{O} \mathbf{z}$

Derleme

Teknoloji alanında yaşanan hızlı gelişmeler her alanda olduğu gibi spor alanını da etkileyerek yeni gelişmelerin ortaya çıkmasına neden olmuştur. Rekabete dayalı video ve bilgisayar oyunlarının hem oynanması hem de izlenmesinin elektronik spor (e-Spor) kavramının doğmasına neden olmuştur. e-Spor, hem fiziksel hem de zihinsel bir takım özellikleri içerisinde barındırmaktadır. Bununla birlikte, sanal veya bilgisayar ortamında oynanması, tesis veya ekipman bakımından modern sporlara göre ciddi finansal kaynak gerektirmemesi, dünyanın her yerinde bu sporu icra edebilme olanağ bireysel ve takım halinde oynanması ve doğasına özgü araç gereci gerektirmesi en önemli özelliklerindendir. Dünya'da en az 400 milyon kişi e-Spor seyircisi, 100 milyondan fazla kişi e-Spor oyuncusu ve ülkemizde en az 7 milyon kişi e-Spor oyuncusu ve izleyici olarak yer almaktadır. -Spor Türkiye'de yeni gelişmekte olan bir spor dalıdır. Literatürde e-Spor'un bir spor olduğunu savunan görüşlerle birlikte spor olmadığını savunan görüşler de mevcuttur. Bu bağlamda, bu çalışmanın amacı eSpor'un tanımından, gelişim sürecinden, dünyada ve ülkemizdeki yerinden bahsetmek ve elektronik ortamda oynanmayan modern sporlarla benzer ve farklı yönlerini ve fiziksel aktivite ile ilişkisini ortaya koymaktır.

\section{e-Sport, Sport and Physical Activity}

\begin{tabular}{lr} 
Abstract & Review \\
\hline Rapid growth in the field of technology is affecting the sports field as well as every area, \\
causing new developments. Playing and watching competitive video and computer games \\
both led to the outbreak of the concept of electronic sports (e-Sport). e-Sport has both \\
physical and mental characteristics. At the same time, it is one of the most important \\
characteristics of being played in virtual or computer environment, not requiring serious \\
financial resources according to modern sports in terms of facility or equipment, is possible \\
to perform this sport everywhere in the world, can be performed individually or with a \\
team and requires particular tools to perform. At least 400 million people are e-Sport \\
audience, more than 100 million people are e-Sport players in the world and at least 7 \\
million people in our country are players and spectators in e-Sport. e-Sport has just started \\
to develop in Turkey. In the literature, there are some considerations which argues that e- \\
Sport is a sport or not a sport. In this context, the aim of this study is to introduce the \\
definition of e-Sport, its development process, its place in the world and in our country and \\
similar and different aspects of modern sports that not played in electronic environments \\
and its relationship with physical activity.
\end{tabular}
* Sorumlu yazar: Rüstem MUSTAFAOĞLU, E-posta: rustem.mustafaoglu@ istanbul.edu.tr, Tel: +90 212414
15 00-40168 


\section{GíRiş}

Oyun, kendiliğinden ortaya çıkan hedefi olmayan, mutluluk getiren serbest bir aktivite olarak tanımlanmaktadır. Oyunlar kendi içerisinde motor ve fiziksel oyunlar, sosyal oyunlar, yapısal oyunlar, kurallı oyunlardır. Oyunlar her açıdan farklı hareket ve düşünme sistemini, alışagelmiş davranış şekillerinin aksine başkalarının davranışlarına ve durumun şartlarına göre kurgulanmış düşünce ve hareket biçimleri olarak da değerlendirilirler (Wood \& Attfield, 2005). Oyunlar insanlara eğitim, fiziksel etkinlik, sağlığın korunması, kendini gerçekleştirme, toplumsal hayata hazırlık, boş zamanları değerlendirme ve eğlence bakımından olanak sağlarken diğer yandan da şiddete yönelmelerine neden olmaktadır. Oyunlar aracılığı ile kişiler güçlü ve zayıf yönlerini kavrayarak gerçek kişiliklerini ortaya çıkarılabilirler (Honey \& Kanter, 2013).

Teknolojik gelişmeler ile birlikte oyunlar yeni bir boyut kazanarak dijital ortama geçiş yapmıştır. Bu dijital oyunlar aynı zamanda video veya bilgisayar oyunları olarak adlandırılır ve birbirlerinin yerine dönüşümlü olarak kullanılırlar (Kirriemuir, 2002). Video/bilgisayar oyunları ve bedensel oyunların her ikisi de bireysel ve çoklu olarak oynanmaktadır. Video oyunlar zihinsel çaba gerektirirken bedensel oyunlar fiziksel ve zihinsel çaba gerektirir. Gelişen video/bilgisayar oyunları insanlara gerçek hayatta yapamayacakları birçok olanağı fantastik bir ortamda veya kişinin kişisel zevkleri dâhilinde sunmaktadırlar. Her iki oyununda yaratıcılığı geliştirmesi ortak yönlerinin bir göstergesi olarak karşımıza çıkmaktadır.

Teknoloji alanında yaşanan hızlı gelişmeler her alanda olduğu gibi spor alanını da etkileyerek elektronik spor (e-Spor) kavramının ortaya çıkmasına neden olmuştur. Teknolojik cihazların ucuzlamasıyla birlikte, atari salonları evlere ve televizyon ekranlarına taşınmıştır. Gelişen oyun konsolları ile birlikte tek kişilik oyunlardan çok kişilik oyunlara geçiş sağlanmıştır. Günümüzde e-Spor kavramının önemli bir gelişme gösterdiği bilinmektedir. e-Spor çevrimiçi oyunlar üzerine kurulu bir spor dalıdır. Profesyonel oyunculuk olarak rekabetçi oyunculuğa eş tutulmaktadır (Argan, Özer, ve Akın, 2006). e-Spor'u, elektronik ortamda oynanmayan modern spor tanımının özellikleriyle karşılaştıracak olursak, gönüllü ve içgüdüsel motivasyona dayalı bir oyunu içermektedir. e-Spor'da koyulan kuralları yönetmek zor olsa da belirli bir süre, kişi sayısı gibi kuralları vardır ve sonucunda bir kazanan taraf bir kaybeden tarafın olduğu karşılaşmalar/müsabakalar vardır. Karşılaşmalar strateji, taktik, takım motivasyonu gibi beceri isteyen yönler içermektedir. e-Sporcu tartışmalı olsa da fiziksel yetenek bağlamında klavye ve mouse kullanarak dakikada 400 hareket yapabilmektedir. Dünya e-Spor Oyunları, Dünya Siber Oyunları gibi organizasyonlar ve Uluslararası e-Spor Federasyonu gibi yöneten organları bulunmaktadır (Jenny, Manning, Keiper, \& Olrich, 2017; Schaeperkoetter ve ark., 2017; Yükçü ve Kaplanoğlu, 2018). Ayrıca, dünya genelinde 2017 yılında 385 milyon kişi gibi geniş bir izleyici kitlesine ulaşılmıştır.

E-Sporlar yüksek derecede el-göz koordinasyonu gerektirmektedir. Bunun yanında takımların maçı kazanmaları için karşı takımların stratejilerinden daha iyi bir strateji belirlemek zorundadırlar (Wagner, 2006). Çoğu oyundaki hareketleri manipüle etmek farenin ve klavyenin hızlı ve doğru hareketlerine dayanmaktadır. Bu gereksinimler oyuncular için 
özelleşmiş ekipmanların gelişmesini sağlayıp yeni bir sektör daha ortaya çıkartmıştır (Örs ve ark., 2018).

Tüm dünyada çok hızlı bir şekilde büyüyen, devasa bütçelere ve takipçi sayısına ulaşan, olumlu ve olumsuz yanları bulanan e-Spor ülkemiz gençlerini de etkisi altına almaya başlamıştır ve bu etki giderek artmaktadır. Ülkemizde e-Spor'lara rekreatif, amatör ve profesyonel düzeyde ortaya çıkan ilgi düzeyine karşın, bu alanda yapılan bilimsel çalışmaların çok az olduğu görülmektedir. Bu çalışmanın amacı, ülkemizde henüz yeni gelişmekte olan e-Spor'un tanımından, gelişim sürecinden, dünyada ve ülkemizdeki yerinden bahsetmek, ayrıca modern sporlarla benzer ve farklı yönlerini ve fiziksel aktivite ile ilişkisini ortaya koymaktır. $\mathrm{Bu}$ araştırmanın en önemli özelliklerinden biri, ülkemizdeki e-Spor konusunda sınırlı olan literatüre sağlanabilecek katkıdır. Türkiye'de e-Spora olan yaklaşımın ve araştırmaların son derece sınırlı sayıda ve kapsamda oluşu, bu çalışmayı önemli kılmaktadır. Çalışma bu konuda yapılacak diğer araştırmalara bir temel oluşturulabilir. Bu özelliği ile de çalışma, Türkiye'de e-Spor konusunda araştırma ve organizasyon yapmak isteyenlere yol gösterici olabilir.

\section{e-Spor'un Tanımı}

e-Spor'un tam olarak ne olduğunu anlamak, kültür, teknoloji, spor ve iş dünyasının birleşmesi ile bu endüstrinin göreceli yeniliği nedeniyle karmaşıktır. Futbol, basketbol ve tenis gibi sporlardan farklı olarak, e-Spor çoklu platformların bir araya gelmesiyle meydana gelmektedir. Sanal atletler veya siber atletler ile de e-Sporcu'lar kastedilmektedir (Argan ve ark., 2006). Wagner (2006), e-Spor'u, insanların bilgi ve iletişim teknolojilerini kullanarak zihinsel ve fiziksel yetenekler geliştiren ve eğiten spor faaliyetleri olarak tanımlamaktadır. Argan ve ark., (2006)'na göre e-Spor, dünyanın bir ucundaki insanın dünyanın diğer ucundaki insanla internet aracılığıyla buluşup oyun oynayabileceği ya da büyük elektronik spor organizasyonları aracılığıyla dünyanın farklı yerlerinden gelen insanların buluşup oyun oynayabilecekleri hem fiziksel hem de zihinsel çaba gerektiren bir spordur. (Hamari \& Sjöblom, 2017) ise e-Spor'u, sporun birincil yönlerinin elektronik sistemler tarafindan kolaylaştırıldığı, hem oyuncuların ve takımların girdilerine hem de e-Spor sisteminin çıktılarına insan-bilgisayar ara yüzleriyle aracılık eden bir spor biçimidir. e-Spor'lar, bilgisayar veya oyun konsolları aracılığı ile amatör veya profesyonel oyuncuların birbirleri ile rekabet ettikleri sanal bir ortamda oynanmaktadır (Jenny et al., 2017). e-Spor, okçuluktaki gibi reaksiyon zamanı, beyzboldaki gibi refleks hareketleri veya satrançtaki gibi düşünmeyi gerektiren bir olgudur (Argan ve ark., 2006). e-Spor'larla ilgili bilinmesi gereken en önemli şeylerden birinin sedanter spor video oyunlarıyla karıştırılmamasıdır. e-Spor'un en popüler türleri, birinci-şahıs-nişancı (First-Pearson-Shooter (FSP)), gerçek-zamanl1-strateji (RealTime-Strategy (RTS)) ve çok-oyunculu-çevrimiçi-rol-yapma-oyunları (Massively Multi-user Online Role Playing Games (MMORPG)) oyunlarıdır (Jonasson \& Thiborg, 2010). 


\section{e-Spor'un Gelişimi}

İlk 1980'li y1llarda atariyle beraber, dijital oyunlar oynanmaya başlanmıştır. 1990'lı yıllarda Atari salonları dijital oyun kültürünün oluştuğu ve geliştiği mekanlar olmuştur. 2000'li yıllardan itibaren internetin yaygınlaşması ile beraber dünya çapındaki erişim ağı oyunları çevrimiçi oynama şekline dönüştürmüştür. Bunun neticesinde oyunlar tek oyunculu olmaktan çıkmış ve çok oyunculu hale gelmiştir (Coşkun ve Öztürk, 2016). 1997 yılında İngilterede eSpor'ların ilk ödüllü turnuvası düzenlenmiştir. 1997 yılında ABD'de “Cyberathlete Professional League" adlı şirket kurulmuştur. 1999 yılında oyun geliştirme şirketi Valve FSP tarzındaki oyunları olan Half-Life'ın üzerinde biraz değişiklikler yaparak "Counter Strike" oyununu üretmişstir. Amerikalılar ve Avrupalıların birinci şahıs nişancı tarzındaki oyunların aksine Kore'liler Koreli bir oyun geliştirme şirketi olan NCSoft tarafından 1998'de çıkarılan "Linage" gibi MMORPG ve RTS oyunlarını oynamayı tercih etmişlerdir (Wagner, 2006). Sektörün en önemli organizasyonlarından biri olan Elektronik Spor Ligi 2000 yılında kuruldu. Ayrıca, 2000 yılında Güney Kore Spor, Turizm ve Kültür Bakanlığı, Bilgi ve İletişim Bakanlığg ve Samsung'un desteğiyle uluslararası e-Spor organizasyonu Dünya Siber Oyunları kuruldu. Dünya Siber Oyunlarının logosu, mavi, kırmızı, sarı ve yeşil renklerinde dört halka kullanır ve siyah bir arka plan ile Olimpiyat Oyunlarının sembolünü anımsatır. Ayrıca, oyunları Olimpiyat hareketiyle ilişkilendirerek, oyuncu (atlet yerine), gençlik festivali, siber oyun etkinliği ve e-Spor gibi oyunları anlatan diğer sportif olmayan kelimeler kullanılmaktadır (Jonasson \& Thiborg, 2010). İki yıl sonra 2002 yılında New York'ta Major League Gaming kuruldu. 2008 y1lında e-Spor'u gerçek bir spor olarak kabul ettirmek amacıyla yola çıkan ve günümüzde 48 üye ülkesi bulunan Uluslararası e-Spor Federasyonu (International e-Sports Federation-IeSF) Güney Kore merkezli olarak. 2016, e-Spor'un Uluslararası Olimpiyat Komitesi (IOC) tarafından tanınması için resmi mektup gönderilmiştir. Uluslararası e-Spor Federasyonu'nun 48 üye ülkesinin 22'sinde e-Spor, Ulusal Olimpiyat Komiteleri tarafından tanınmaktadır. Son olarak Asya Olimpiyat Konseyi, 17 Nisan 2017 tarihinde yaptığı açıklamada 2022'de Çin'de düzenlenecek olan Asya Oyunları'nda e-Spor'un resmi bir oyun olarak madalya yarışmalarında yer alacağı duyuruldu. Ayrıca, e-Spor'un Uluslararası Olimpiyat Komitesi tarafından Paris 2024 Olimpiyat Oyunlarına dahil edilmesine karar verilmiş olup, madalya yarışmalarında yer alıp almayacağı ile ilgili henüz bir karar verilmiş değildir (DiFrancisco-Donoghue \& Balentine, 2018).

\section{Dünyada ve Ülkemizde e-Spor'un Yeri}

Günümüzde Dünya kupas1, Avrupa kupası, Uluslararası Lig, e-Spor Amatör Ligi, e-Spor Profesyonel Ligi gibi ulusal ve uluslararası düzeyde resmi ve özel pek çok e-Spor turnuvası düzenlenmektedir (Argan ve ark., 2006). Profesyonel e-Spor turnuvalarına yarışmacı olarak katılan sporcular, e-Spor'u profesyonel olarak yapan ve kendi ülkelerinde yapılan turnuvalar sonucunda başarılı olan takım veya bireysel olarak yarışmacı olma hakkını kazananlardır. Newzoo'nun 2017 yılındaki raporuna göre dijital oyun sektörü 2016 y1lında 101,1 milyar dolara ulaşmıştır. Aynı raporda 2020 yılında bu rakamın 128,5 milyar dolara ulaşması beklenmektedir ve mobil oyun sektörünün 46,1 milyar dolar hasılat ile Hollywood film sektörünü geride bıraktığı belirtilmiştir (Aktuna ve Ünlüönen, 2017). 
Günümüzde Paris Saint Germain, Manchester City, Schalke 04 gibi önemli takımların bu alana girerek önemli yatırımlar yapmaktadır. Gençler, çocuklar bir sporla veya bir kulüple eSpor vasıtasıyla tanışmaktalar. Taraftarlık olgusunun oluşmaya başladığı dönem belki de ilk kez e-Spor ile oluyor, kulüplerin de bu anlamda e-Spor'a yatırım yaptığını görüyoruz. Diğer yandan üniversite öğrencilerinin bazılarının mevcut eğitim sisteminden kariyer sahibi olma konusunda ümitsizlikleri ve üniversiteden mezun olduktan sonra gelecek kaygısı onları eğitim sisteminden uzaklaştırmaktadır. Bazı öğrenciler gelecekte profesyonel oyuncu olmayı veya oyunlarını yayınlayarak geçimlerini kazanmayı düşünmektedirler (Kocadağ, 2017).

Ülkemizin ilk e-Spor takımı, 2003 yılında kurulmuş olan Dark Passage takımıdır. e-Spor'lara artan taleple birlikte, 2015 yılında Beşiktaş e-Spor Kulübü, 2016 yılında 1907 Fenerbahçe eSpor ve Galatasaray eSports katımları kurularak, League of Legends oyunu için e-Spor takımlarına resmi destek vermeye başlamışlardır. Bunların dışında ülkemizde 2005 yılında kurulmuş Team Turquality ve 2008 yılında kurulmuş HWA Gaming takımları da vardır. Bahçeşehir Üniversitesi'nin League of Legends takımı olan BAU SuperMassive de, başarılı takımlar arasındadır (Üçüncüoğlu ve Çakır, 2017). 2011 yılında kurulan Türkiye Dijital Oyunlar Federasyonu ile devlet tarafından federasyon seviyesinde tanınan e-Spor, 2013 y1lında bu federasyonun kapanması ile asbaşkanlık seviyesine inmiştir. 24/04/2018 tarihli ve 277144 sayılı Bakanlık Oluru ile Türkiye e-Spor Federasyonu kurulmuş olup Gençlik ve Spor Bakanlığı bünyesinde hizmet vermektedir. Profesyonel liglere katılacak oyunculara, Gençlik ve Spor Bakanlığı-Spor Genel Müdürlüğü tarafından 2014 yılından itibaren e-Sporcu lisansı verilmektedir.

\section{e-SPOR ve SPOR}

\section{e-Spor Modern Sporun Bir Dalı Midır?}

e-Spor'un bir spor olduğunu savunan görüşlerle birlikte spor olmadığını savunan görüşler de mevcuttur. Birçok kişi, özellikle "geleneksel”" spor taraftarları, e-Spor'ların bir spor olarak adlandırılamayacağı görüşündedir. Çoğu kişi "spor" kelimesini düşündüğünde, ilk akla gelen şeylerden birinin bilgisayar başında oynanan video oyunları olduğu söylenemez. Benzer olarak bir üniversite kampüsünde "sporcu öğrenci" kelimesini duyduğunuzda, bilgisayar başında oturup oyun oynayan birini sporcu olarak düşünmüyoruz. Aslında, spor bir bilgisayar oyunu önünde saatlerce oturmanın tam tersi olarak algıladığımız aktivitelerdir (DiFranciscoDonoghue \& Balentine, 2018). Sporcunun fiziksel uygunluk ve fiziksel aktivite durumu tüm spor aktivitelerinde önemli bir unsurdur. Bununla birlikte, e-Spor'cuların oynadıkları oyunlarda başarılı olabilmeleri için reflekslerini, bilişsel fonksiyonlarını ve el-göz koordinasyonlarını iyi bir şekilde kullanmaları gerektiği göz ardı edilmektedir (Witkowski, 2012). Diğer yandan yazarlar Wagner'in genişletilmiş e-Spor tanımı, çok kapsamlı olsa da, eSpor'u tam olarak tanımlayamadığı görüşündedirler. Yazarların Wagner'in tanımının tam olarak uymadığına inandıkları kısmın, spor aktivitelerinin sadece zihinsel ya da fiziksel olması görüşüdür. Yazarlara göre bir oyunu bir spordan ayıran en önemli özelliklerden birinin sporun fiziksel becerilerin uygulanması olduğudur (Jenny ve ark., 2017; Suits, 2007). Sarf edilen fiziksel çabanın derecesine göre değerlendirildiğinde basketbol veya futbolun, satrançtan farkı göz önüne alınabilir. Futbolda uzun süre bedenin hareketi söz konusuyken 
satrançta sadece bir figürün alınıp başka yere konması ile oynanmaktadır. $\mathrm{Bu}$ durumda satranç ta mı spor sayılmalıdır? Parry (2018), e-Spor oyunlarının spor olmadığını savunmakta çünkü ona göre onlar yetersiz "insan" lardır; doğrudan fizikselliğe sahip değillerdir; çünkü belirleyici bütün vücut kontrolü ve becerilerini kullanamazlar ve insanın gelişimine katkıda bulunamazlar. Rekabetçi video oyunlarının spora benzediği iddia edilse de, spor olarak nitelendirilemez. Bilgisayar oyunları sadece — oyundurlar (Parry, 2018). Çağdaş toplumlarda e-Spor, genellikle spor olarak kabul edilmez, en azından modern spor değildir. Bunun yerine, e-Spor bir karşı kültür ya da modern sporun alternatifi olarak öne çıkabileceği düşünülmektedir. Diğer yandan, Güney Kore, Çin, Rusya, Macaristan ve Danimarka gibi bazı ülkelerde e-Spor resmi bir spor olarak kabul edilmektedir (Jonasson \& Thiborg, 2010).

\section{e-Spor'un Modern Sporlarla Benzer Yönleri}

Elektronik ortam dişında oynanan modern sporun tanımında yer alan özelliklerle e-Spor'un bazı benzer noktaları bulunmaktadır. Modern sporun tanımındaki özellikler, gönüllü ve içgüdüsel motivasyona dayalı bir oyunu içermesi, belirli bir süre, kişi sayısı gibi kurallarının olması, sonucunda bir kazanan taraf bir kaybeden tarafin olduğu karşılaşma/müsabaka olması, şans değil becerinin olması, fiziksel yeteneği içermesi, yerel ilginin ötesinde geniş izleyici kitlesine sahip olması, kurumsal istikrarı sağlamış olması sayılmaktadır. e-Spor'u, elektronik ortamda oynanmayan modern spor tanımının özellikleriyle karşılaştıracak olursak, gönüllü ve içgüdüsel motivasyona dayalı bir oyunu içermektedir. e-Spor'da koyulan kuralları yönetmek zor olsa da belirli bir süre, kişi sayısı gibi kuralları vardır ve sonucunda bir kazanan taraf bir kaybeden tarafın olduğu karşılaşmalar/müsabakalar vardır. Karşılaşmalar strateji, taktik, takım motivasyonu gibi beceri isteyen yönler içermektedir. e-Sporcu tartışmalı olsa da fiziksel yetenek bağlamında klavye ve mouse kullanarak dakikada 400 hareket yapabilmektedir. Dünya e-Spor Oyunları, Dünya Siber Oyunları gibi organizasyonlar ve Uluslararası e-Spor Federasyonu gibi yöneten organları bulunmaktadır (Jenny ve ark., 2017; Schaeperkoetter ve ark., 2017). Ayrıca, dünya genelinde 2017 yılında 385 milyon kişi gibi geniş bir izleyici kitlesine ulaşılmıştır (Yükçü ve Kaplanoğlu, 2018).

Hem e-Spor hem de modern spor bireysel ya da takım olarak gerçekleştirilmektedir. Başarı için bireysel yeteneklerin diğer yarışmacılara karşı daha iyi olması ve takım olarak eş zamanlı hareket etmenin ve uyumun yüksek düzeyde gerçekleşmesi gerekmektedir. Her iki spor da zihinsel çaba içermektedir (Akın, 2008). Modern sporun futbol, basketbol, voleybol gibi çeşitli kategorileri olup hepsinin ayrı turnuvaları, ligleri düzenlenmektedir. e-Spor'un da League of Legends, Dota 2, Counter Strike: GO gibi çeşitli kategorileri var ve hepsinin de y1l içinde farklı zamanlarda turnuvaları ve ligleri düzenlenmektedir. Modern sporlarda olduğu gibi e-Spor'larda da çeşitli dallar (FPS, RTS, MMORPG ve spor oyunları) bulunmaktadır (Hamari \& Sjöblom, 2017). Bu dalların bir kısmı bireysel müsabakaya açılırken, diğer bir kısmı ise takım halinde müsabakaya açılmaktadır. e-Spor dallarının da modern spor dalları gibi yıldız oyuncuları, hayran kitlesi, takımları, formaları ve ligleri vardır (Jenny et al., 2017). e-Spor, modern sporlar gibi düzenli eğitim, takım çalışması veya önceden planlanan taktiklerin mükemmel şekilde uygulanması gibi benzerliklere de sahiptir (Hutchins, 2006). e- 
Spor, daha çok genç kuşaktan oluşur, ortalama bir e-Spor oyuncusu 15 ila 25 yaşları arasındadır ve haftada 3-4 kez 2-4 saat antrenman yapmaktadır (Martončik, 2015).

e-Spor'un spor olup olmayacağını daha detaylı tartışacak olursak, modern sporun seminal tanımlarını spor sosyolojisi (Guttmann, 1978) ve spor felsefesine (Suits, 2007) göre gözden geçirelim. Bu iki tanıma uygun olarak, e-Spor'un bir spor olarak nitelendirilip nitelendirilemeyeceğine belirlemek için bir aktivitenin bir spor olarak değerlendirilmesi için aşağıdaki yedi özelliğe sahip olmalıdır.

\section{Oyun}

Guttmann (1978), oyunun tüm sporlar için temel oluşturduğunu iddia etmektedir. Bu, eğlenmek için yapılan gönüllü, içsel olarak motive edilmiş aktiviteyi içermektedir. $\mathrm{Bu}$ bağlamda, e-Spor katılımcıları gönüllü olarak eğlence için video oyunları oynarlar ve sporun bu özelliğini yerine getirmektedirler.

\section{Düzenlenme}

Suits (2007), spor aktiviteleri kurallara bağlı kalınarak hedefe yönelik faaliyetler olduğunu ileri sürmektedir. Benzer olarak, Guttmann'a (1978) göre sporlar düzenlenir ve kurallara tabidirler. Tipik bir e-Spor turnuvasında, takımlar dört ila beş oyuncudan oluşur, belirli bir zaman periyodu boyunca (örneğin, 1 saat veya 45 dakika), seçilmiş bir video oyunu (örneğin, League of Legends) oynatılarak, birden fazla turda rekabet ederler. $\mathrm{Bu}$ açıdan değerlendirilecek olursa, e-Spor'un kurallarla düzenlenmiş bir olgu olduğu görülmektedir.

\section{Rekabet}

Tüm spor dalları rekabet içerirler. Guttmann (1978), spor, kazanma/kaybetme ile sonuçlanan rekabeti içermelidir. e-Sporlar, sonunda kazananların/kaybedenlerin olduğu rekabetçi video oyunlarını içermektedir. Şüphesiz, e-Spor rekabeti ve genellikle çok yoğun bir rekabeti içermektedir.

\section{Beceri/Yetenek}

Suits'e (2007) göre spor, şansın kazanmanın tek nedeni olmadığı yetenek gerektiren bir oyun içermelidir. e-Spor'da oyuncular ekrandaki avatarlarını (yani, bir video oyunundaki oyuncuyu temsil eden simgeyi) etkili bir şekilde yönetmek için oyuncular mouse/oyun konsolu düğmelerini manipüle etmek için ustaca bir koordinasyona gereksinim duymaktadırlar. Profesyonel bir oyun turnuvasında başarılı olmak için; hızlı refleksler, iyi el becerisi ve mükemmel el-göz koordinasyonu sergilemeniz gerekmektedir. Bununla birlikte, başarılı bir e-Spor'cunun, oynadığı oyunu çözebilmesi için oyun mantığına (taktik ve strateji), kapsamlı bilgiye ve becerilere sahip olması gerekmektedir (Hemphill, 2005). eSpor'lar beceri gerektirse de, sporun ortak tanımları, aktivitede yer alan becerilerin fiziksel olması gerektiğine işaret etmektedir.

\section{Fiziksellik}

Suits (2007)'e göre fiziksellik, sporu oyunlardan ayırt eden en önemli özelliktir; sporlar şans değil, beceri oyunları iken, beceriler de fiziksel olmalıdır. Guttmann (1978) da sporun fiziksel yarışmalardan oluşması gerektiğini belirtmektedir. Bu nedenle, bir oyunun bir spor olarak 
görülmesi için, fiziksel beceri (ler) içeriyor olması ve bu fiziksel becerilerin bir görevin başarılı bir şekilde tamamlanmasına doğrudan etki etmesi gerekmektedir. Basketbol oynarken, bir atışı yapmanın şekli, atışın başarılı olup olmadığı konusunda doğrudan bir etkiye sahip olmaktadır. Basketbolda başarılı olmak için büyük fiziksel beceriye gereksinim vardır. Bununla birlikte, pek çok oyun, masa üstü çeşitliliğe sahip olanlar bile, oyunda başarılı olmak için bir oyuncunun fiziksel becerilerini gerektirebilmektedir. Başarılı bir Jenga oyuncusu olmak büyük konsantrasyon, strateji ve hassas ince motor koordinasyonu gerektirir. Böyle kesin bir fiziksel beceri, ancak aylar hatta yıllar boyunca geliştirilebilir. Jenga, o zaman, bir spor mudur? Benzer şekilde, e-Spor'lar da, mouse/konsollar aracılığıyla bir avatarın başarılı bir şekilde yönlendirilmesi kesin bir fiziksel beceri gerektirir. Jenga'da olduğu gibi, e-Spor'da başarılı bir fiziksel beceri kazanmak aylar ve muhtemelen yıllar sürmektedir. O zaman e-Spor'lar, spor olarak kabul edilebilir mi?

\section{Geniş izleyici kitlesi}

Suits (2007), bir sporun sadece yerel bir cazibe veya merak oluşturan bir oyunun ötesine geçmesi gerektiğini ve geniş bir izleyici kitlesine sahip olması gerektiğini iddia etmektedir. eSpor oyunları 2017 yılında 191 milyon e-Spor hayranı ve 194 milyon ara sira e-Spor izleyenlerle birlikte toplam 385 milyon e-Spor izleyicisi kitlesine ulaşmıştır. 2018 yılında toplam e-Spor izleyicisi 389 milyon, 2019 yllında 427 milyon ve 2020 y1lında 589 milyon olacağ1 tahmin edilmektedir (Yükçü ve Kaplanoğlu, 2018). Böylece, e-Spor'un geniş bir takipçisi ve izleyici kitlesi vardır diyebiliriz.

\section{Kurumsallaşma}

Stabilite göstermek uzun zaman gerektirir. Kurumsallaşma, uzun bir tarihe sahip olan bir faaliyettir: (a) kurallar geliştirilir ve standartlaştırılır; (b) oyunun öğrenilmesi resmileşir; (c) uzmanlık alanları gelişir; ve (d) antrenörler, eğitmenler, yetkililer ve yönetim organları ortaya çıkar (Suits, 2007). Bu bağlamda e-Spor'un popülaritesi yadsınamazken, kurumsal organizasyon ve düzenlemedeki istikrar hala kanıtlanmış değildir diyebiliriz

\section{e-Spor’un Modern Sporlardan Farklı Yönleri}

Sorulması gereken en önemli soru, sporun hangi kısımlarının veya yönlerinin bir spor etkinliğinde elektronik ve/veya bilgisayar aracılığı olması gerekiyor olmalı ki o spor e-Spor olarak kabul edilsin. Bir spor ile e-Spor arasındaki temel farkın, spor/oyun sonuçlarını belirleyen oyuncu veya takım faaliyetlerinin nerede ortaya çıkmasıyla ilgilidir. Modern sporlarda, spor uygulayıcılarının spor faaliyetlerine yardımcı olmak için elektronik ve bilgisayarlı sistemler kullanabilmesine rağmen, tüm sonuç tanımlayıcı faaliyetlerin "gerçek dünyada" gerçekleştiği görülmektedir. Bununla birlikte, e-Spor'da, sonuç tanımlayıcı faaliyetlerin "sanal bir dünyada" ya da başka bir deyişle elektronik/dijital/bilgisayar aracılı ortamlarda gerçekleştiği görülmektedir. e-Sporcular gerçek dünyada insan-bilgisayar ara yüzünü (insan girdileri: mouse, klavye, mikrofon, hareket sensörleri, ağırlık sensörleri, hızlanma sensörleri. Bilgisayar çıktıları: görüntü araçları, dokunma duyusuyla ilgili geri besleme, ses cihazları) kapsayan spor ekipmanlarını kullanırlar ve oyun alanları elektronik sistemlerdir. Modern sporcular ise insan-fiziksel nesne ara yüzünü kullanırlar veya herhangi bir donanıma ihtiyaçları olmayabilir ve oyun alanları gerçek dünyadır (Hamari \& Sjöblom, 2017). e-Spor'larda oyun kategorisi ne olursa olsun araç ve gereçleri aynıdır ve büyük 
finansal kaynak gerektirmezler. e-Sporda kullanılan araç ve gereçler (klavye, mouse, mouse pad, kulaklık, gözlük, internet hızı, eldiven, özel forma, takım forması, milli takım forması) modern sporlarda branşa özgü kullanılan araç ve gereç farklılı̆̆ gibi farklılık göstermemektedir. e-Spor'lar fiziksel çabadan çok düşünsel çabayı ön plana çıkarmaktadır. Modern sporlar ise düşünsel çaba ile birlikte fiziksel çabayı da ön plana çıkarmaktadır (Akın, 2008). Modern sporcular antrenmanlarını branşlarına özgü ortamlarda (saha, havuz, salon vb.) yaparken, e-Sporcuların antrenman yaptıkları ortam bilgisayar ortamıdır ve evde veya internet kafede yerel ağ bağlantısı kurarak yada internete bağlanarak bireysel veya takım halinde yapmaktadırlar (Argan ve ark., 2006). e-Spor oyunlarında başarıyı etkileyecek faktörleri sınıflandırdığımızda bunlar; düşünme hızı, önsezi, zekâ, takım oyunu, el çabukluğu, görme yeteneği, konsantrasyon ve liderliktir. Bütün bu unsurlar sporcuların başarıya ulaşmasında önemli bir etkendir (Akın, 2008). Bu yüzden çoğu yarışmada e-Sporcu'lar kendi arayüz araç ve gereçlerini getirebilir ve yarışmaya onlarla katılabilirler ve bu araç ve gereçlerin üzerinde oyuncunun takım sponsorlarının logolarını taşırlar. Günümüzde özellikle teknoloji firmaları, hem reklam hem de finansal destek amaçlı profesyonel e-Sporcu takımları ile anlaşma yapmaktadır. Takımlar kendilerini destekleyen bu sponsorları web sitelerinde ve takım formalarında belirtirler. e-Spor alanında başlıca sponsor firmalar Intel, Coca-Cola, Red Bull, Mountain Dew, T-Mobile, Mobil 1, Audi, Airbus, ASUS, HTC, Logitech, Razer ve Türk Hava Yolları'dır.

\section{e-Spor ve Aktif Video Oyunları}

Daha önceki bölümde belirtildiği gibi sedanter video oyunlarına harcanan uzun sürelerin vücut kompozisyonu, aktivite düzeyi, benlik saygısı, sosyal davranış ve akademik başarı gibi bir dizi olumsuz sağlık ve davranışsal göstergelerle ilişkili olduğu saptanmıştır. Bu nedenle, sağlık alanında çalışan araştırmacılar problemin bir parçası yerine çözümün bir parçası olacak ekran tabanlı teknolojiyi kullanan yeni oyunlar geliştirmeyi hedeflemiştir. Bu oyunlar, aktif video oyunları olarak adlandırılmakta ve bilinen masabaşı sedanter video oyunlarından en önemli farklı yanının, aktif video oyunları fiziksel aktivite gerektiren ekran tabanlı hareketler içeriyor olmasıdır. Aktif video oyunları, kullanıcı tarafından yapılan fiziksel hareketleri simüle etmek için hareket algılama sensörleri ve yazılımını kullanır ve bunları bir ekran avatarı ile görüntüler. Bunlar sıklıkla Exergames olarak adlandırılırlar ve hareket sensörü zemini, kızılötesi sensörleri veya kameralar kullanırlar. Aktif video oyunları, Nintendo Wii, X-box Kinect ve PlayStation 4 gibi sistemlerde oynanmaktadır. Oh \& Yang (2010) aktif video oyunlarını denge, esneklik, kuvvet ve kardiyovasküler aktiviteleri olmak üzere fiziksel aktiviteyi uyarıcı herhangi bir video oyunu olarak tanımlamıştır. Amerikan Spor Hekimliği Koleji (ACSM) sağlık ve fitnes için günde en az 30 dakika aerobik, nöromotor veya spor aktiviteleri içeren orta şiddetli fiziksel aktiviteye haftada 5 gün veya günde en az 20 dakika haftada 3 gün yüksek şiddetli fiziksel aktiviteye katılmayı önermektedir. ACSM, yüksek şiddetli egzersizleri, solunum, terleme ve kalp hızında önemli artışlar olarak tanımlarken; orta şiddeti bu özelliklerde belirgin artış olarak bildirmiştir (Haskell ve ark., 2007). Bir metaanalizde aktif video oynamanın enerji tüketiminde, kalp hızında, metabolik eşdeğerde (MET), $\mathrm{VO}_{2} \max$ ve fiziksel aktivite düzeyinde artışa neden olduğu bildirilmiştir (Gao, Chen, Pasco, \& Pope, 2015). Diğer bir meta-analizde ise aktif video oyunlar ile enerji tüketimi arasında güçlü bir ilişki olduğu, katılımcıların büyük çoğunluğunun ACSM'nin önerdiği orta şiddetli fiziksel aktivite düzeyine ulaştığını bildirmiştir (Sween ve ark., 2014). Aktif video oyunları 
dinlenme durumuna ve sedanter video oyunlarına göre daha fazla enerji tüketimine neden olduğu ve aktif video oyunları sirasında tüketilen enerjinin modern sporlara ve fiziksel aktiviteye göre daha az olduğu bildirilmiştir (Ballard, Gray, Reilly, \& Noggle, 2009; Daley, 2009; Foley \& Maddison, 2010; Jenny \& Schary, 2015; Peng, Crouse, \& Lin, 2013; Peng, Lin, \& Crouse, 2011). Aktif video oyunu oynama sırasında enerji tüketimi, orta yoğunlukta yürüyüşle karşılaştırılabilir olduğu ileri sürülmüştür (Graf, Pratt, Hester, \& Short, 2009). Diğer bir çalışmada ise kısa sürelerle aktif video oyunlarını oynamanın, yürüme, zıplama ve tempolu koşu gibi hafif-orta şiddetli geleneksel fiziksel aktivitelere benzer aktivite yapmayla eşdeğer olduğu bildirilmiştir (Biddiss \& Irwin, 2010; LeBlanc ve ark., 2013; Maddison ve ark., 2007). Randomize kontrollü çalışmada ise aktif bir video oyunu oynayan grupta kontrol grubuna göre kilolu ve obez çocuklarda vücut kitle indeksinde ve vücut kompozisyonunda küçük fakat kesin bir etkiye sahip olduğu rapor edilmiştir (Maddison ve ark., 2011).

Günümüzde, e-Spor sedanter video oyunlarını içermektedir. Araştırmacılar video oyunlarının koordinasyon ve çevikliğe gereksinim duyduğunu iddia ederken, şu anda bir e-Sporcu, mouse'u manipüle etmek için sadece ince motor hareketleri sergilemektedir (Crawford \& Gosling, 2009). Henüz aktif video oyunları eğlence ya da egzersiz için kullanılmaktadır, rekabetçi e-Spor oyunları kapsamına henüz girmemiştir. Eğlence için video oyunları oynayarak önemli zaman harcayan çocuklar için, fiziksel olarak aktif katılım sunan aktif video oyunları enerji harcamasını teşvik etmek için güvenli, eğlenceli ve değerli bir araç gibi görünmektedir. Video oyunlarının kitlesel popülaritesi nedeniyle, aktif video oyunlarının obezite ile mücadele etmek ve fiziksel aktiviteyi arttırmak için bir araç olabileceği düşüncesindeyiz. Bununla birlikte, inaktiviteye bağlı olarak enerji tüketiminde azalma ve olası obezite gelişimi ile mücadele etmek için e-Sporcu'ların severek aktif olarak katılabilecekleri ve katılımlarını sürdürebilecekleri egzersiz, rekrasyonel aktiviteler ve spor gibi fiziksel aktivitelere katılımını arttırmaya yönelik yapılandırılmış haftalık programların oluşturulması hedeflenmelidir.

\section{SONUÇ}

e-Spor'un spor olarak benimsenip benimsenmeyeceği konusunda, sporun doğası ve tarihsel tanımları hakkında bir anlayışın önemli olduğu görülmektedir. e-Spor'un, oyun ve rekabet içermesi, kurallara göre düzenlenir olması, beceri gerektirmesi ve geniş bir izleyici kitlesine sahip olmasına rağmen fiziksellik ve kurumsallaşmada önemli eksiklikler olarak bilinmektedir. Günümüzün popüler e-Spor formunu oynamak için yüksek miktarda fizikselliğe gerek duyulmamaktadır ve modern sporun özelliklerinin sadece birkaçını veya çoğunluğunu içinde barındıran bir olgunun spor olarak değerlendirilebilecek bir faaliyet olması gerektiği savunulmaktadır. Ancak, gelecekteki e-Spor'a yüksek miktarda fizikselliğe sahip olan aktif video oyunları dahil edilirse, bu, e-Spor'ların genel populasyon tarafindan "spor" olarak kabul edilmesi için çok fazla güven sağlayabilir. Günlerinin büyük bir çoğunluğunu bilgisayar başında video oyunları oynayarak geçiren e-Sporcu'ların önerilen haftalık fiziksel aktiviteye katılım sürelerine ulaşmaları için yönlendirilmeli ve teşvik edilmelidirler. 


\section{KAYNAKLAR}

Akın, E. (2008). Elektronik spor: Türkiye'deki elektronik sporcular üzerine bir araştırma. (Yüksek lisans tezi). Anadolu Üniversitesi Sağlık Bilimleri Enstitüsü.

Aktuna, H. C., ve Ünlüönen, K. (2017). Yeni bir turizm çeşidi olarak elektronik spor turizmi. Gazi Üniversitesi Turizm Fakültesi Dergisi, 2(2017), 1-15.

Argan, M., Özer, A., Akın, E. (2006). Elektronik spor: Türkiye'deki siber sporcuların tutum ve davranışlanı. Spor Yönetimi ve Bilgi Teknolojileri Dergisi, 1(2), 1-11.

Ballard, M., Gray, M., Reilly, J., Noggle, M. (2009). Correlates of video game screen time among males: body mass, physical activity, and other media use. Eating behaviors, 10(3), 161-167.

Biddiss, E., \& Irwin, J. (2010). Active video games to promote physical activity in children and youth: a systematic review. Archives of pediatrics \& adolescent medicine, 164(7), 664-672.

Coşkun, E., ve Öztürk, M. C. (2016). Steam dünyas1: dijital oyun bloglarına yönelik bir değerlendirme. Gümüşhane Üniversitesi İletişim Fakültesi Elektronik Dergisi, 4(2), 678-702.

Crawford, G., \& Gosling, V. K. (2009). More than a game: Sports-themed video games and player narratives. Sociology of Sport Journal, 26(1), 50-66.

Daley, A. J. (2009). Can exergaming contribute to improving physical activity levels and health outcomes in children? Pediatrics, 124(2), 763-771.

DiFrancisco-Donoghue, J., \& Balentine, J. R. (2018). Collegiate eSport: Where Do We Fit In? Current sports medicine reports, 17(4), 117-118.

Foley, L., \& Maddison, R. (2010). Use of active video games to increase physical activity in children: a (virtual) reality? Pediatric exercise science, 22(1), 7-20.

Gao, Z., Chen, S., Pasco, D., Pope, Z. (2015). A meta-analysis of active video games on health outcomes among children and adolescents. Obesity reviews, 16(9), 783-794.

Graf, D. L., Pratt, L. V., Hester, C. N., Short, K. R. (2009). Playing active video games increases energy expenditure in children. Pediatrics, 124(2), 534-540.

Guttmann, A. (1978). From ritual to record: Columbia University Press (p, 224). New York.

Hamari, J., \& Sjöblom, M. (2017). What is eSports and why do people watch it? Internet research, $27(2), 211-232$.

Haskell, W. L., Lee, I.M., Pate, R. R., Powell, K. E., Blair, S. N. et al. (2007). Physical activity and public health: updated recommendation for adults from the American College of Sports Medicine and the American Heart Association. Circulation, 116(9), 1081-1093.

Hemphill, D. (2005). Cybersport. Journal of the Philosophy of Sport, 32(2), 195-207. 
Honey, M., \& Kanter, D. E. (2013). Design, make, play: Growing the next generation of STEM innovators: (s,50-70).New York: Routledge.

Hutchins, B. (2006). Computer gaming, media and e-Sport. In V. Colic-Peisker, F. Tilbury, \& B. McNamara (Eds.), TASA 2006 Conference Proceedings (pp. 1-9). Perth WA Australia: Sociologial Association of Australia.

Jenny, S. E., Manning, R. D., Keiper, M. C., Olrich, T. W. (2017). Virtual (ly) athletes: Where eSports fit within the definition of "sport". Quest, 69(1), 1-18.

Jenny, S. E., \& Schary, D. P. (2015). Motion-based video game and authentic wall/rock climbing: motivations and perceptions of novice climbers. International Journal of Technology in Teaching \& Learning, 11(1), 35-49.

Jonasson, K., \& Thiborg, J. (2010). Electronic sport and its impact on future sport. Sport in Society, 13(2), 287-299.

Kirriemuir, J. (2002). Video gaming, education and digital learning technologies. D-lib Magazine, $8(2), 1-12$.

Kocadağ, M. (2017). Elektronik spor kariyeri ve eğitim. Doğu Anadolu Sosyal Bilimlerde Eğilimler Dergisi, 1(2), 49-63.

LeBlanc, A. G., Chaput, J.P., McFarlane, A., Colley, R. C., Thivel, D. et al. (2013). Active video games and health indicators in children and youth: a systematic review. PloS one, 8(6), e65351. doi: 10.1371/journal.pone.0065351.

Maddison, R., Foley, L., Ni Mhurchu, C., Jiang, Y., Jull, A. et al.(2011). Effects of active video games on body composition: a randomized controlled trial. The American journal of clinical nutrition, 94(1), 156-163.

Maddison, R., Mhurchu, C. N., Jull, A., Jiang, Y., Prapavessis, H. et al. (2007). Energy expended playing video console games: an opportunity to increase children's physical activity? Pediatric exercise science, 19(3), 334-343.

Martončik, M. (2015). e-Sports: Playing just for fun or playing to satisfy life goals? Computers in human behavior, 48, 208-211.

Oh, Y., \& Yang, S. (2010). Defining exergames \& exergaming. Proceedings of Meaningful Play, 117.

Örs, A., Çolak, E., Son, M., Güzelordu, D., Çolak, T. et al.(2018). Spor Bilimleri Fakültesi öğrencilerinin e-spor bilgi düzeylerinin araştırılması. Kocaeli Üniversitesi Sosyal Bilimler Dergisi, KOSBED, 35: 121 - 127.

Parry, J. (2018). E-sports are Not Sports. Sport, Ethics and Philosophy, 1-16. https://doi.org/10.1080/17511321.2018.1489419. 
Peng, W., Crouse, J. C., \& Lin, J.H. (2013). Using active video games for physical activity promotion: a systematic review of the current state of research. Health Education \& Behavior, 40(2), 171-192.

Peng, W., Lin, J.H., \& Crouse, J. (2011). Is playing exergames really exercising? A meta-analysis of energy expenditure in active video games. Cyberpsychology, Behavior, And Social Networking, 14(11), 681-688.

Schaeperkoetter, C. C., Mays, J., Hyland, S. T., Wilkerson, Z., Oja, B. et al. (2017). The "new" student-athlete: An exploratory examination of scholarship eSports players. Journal of Intercollegiate Sport, 10(1), 1-21.

Suits, B. (2007). The elements of sport. (W.J. Morgan Ed.) In Ethics in sport. Champaign: Human Kinetics. pp: 9-19.

Sween, J., Wallington, S. F., Sheppard, V., Taylor, T., Lianos, A. A. et al. (2014). The role of exergaming in improving physical activity: a review. Journal of Physical Activity and Health, 11(4), 864-870.

Üçüncüoğlu, M., ve Çakır, V. (2017). Modern spor kulüplerinin espor faaliyetlerine ilgi gösterme nedenleri üzerine bir araştırma. İnönü Üniversitesi, Beden Eğitimi ve Spor Bilimleri Dergisi, $4(2), 34-47$.

Wagner, M. G. (2006). On the Scientific Relevance of eSports.. In H. R. Arabnia (ed.), International Conference on Internet Computing (p./pp. 437-442), : CSREA Press. ISBN: 1-60132-005-1.

Witkowski, E. (2012). On the digital playing field: How we "do sport" with networked computer games. Games and Culture, 7(5), 349-374.

Wood, E., \& Attfield, J. (2005). Play, learning and the early childhood curriculum London: SAGE Publications Ltd. DOI: 10.4135/9781446280393.

Yükçü, S., ve Kaplanoğlu, E. (2018).UíK e-Spor Endüstrisi. Uluslararası İktisadi ve İdari İncelemeler Dergisi, (17. UİK Özel Sayıs1): 533-550. DOI: 10.18092/ulikidince.435207. 